\title{
Modulating the wayward T cell: New horizons with immune checkpoint inhibitor treatments in autoimmunity, transplant, and cancer
}

\author{
Leonard H. Calabrese $^{\mathrm{a}, *}$, Roberto Caporali ${ }^{\mathrm{b}}$, Christian U. Blank ${ }^{\mathrm{c}}$, Allan D. Kirk ${ }^{\mathrm{d}}$ \\ a Cleveland Clinic, Cleveland, $\mathrm{OH}$, United States \\ ${ }^{\mathrm{b}}$ University of Milan, Department of Clinical Sciences and Community Health and Rheumatology Division, ASST Pini-CTO Hospital, Milan, Italy \\ ${ }^{\mathrm{c}}$ The Netherlands Cancer Institute, Amsterdam, The Netherlands \\ ${ }^{\mathrm{d}}$ Department of Surgery, Duke University School of Medicine, Durham, NC, United States
}

\section{A R T I C L E I N F O}

\section{Keywords:}

Costimulation modulation

Coinhibition modulation

Immune checkpoints

Autoimmunity

Transplantation

Cancer

\begin{abstract}
A B S T R A C T
The T-cell response is regulated by the balance between costimulatory and coinhibitory signals. Immune checkpoints are essential for efficient T-cell activation, but also for maintaining self-tolerance and protecting tissues from damage caused by the immune system, and for providing protective immunity. Modulating immune checkpoints can serve diametric goals, such that blocking a coinhibitory molecule can unleash anti-cancer immunity whereas stimulating the same molecule can reduce an over-reaction in autoimmune disease. The purpose of this review is to examine the regulation of T-cell costimulation and coinhibition, which is central to the processes underpinning autoimmunity, transplant rejection and immune evasion in cancer. We will focus on the immunomodulation agents that regulate these unwanted over- and under-reactions. The use of such agents has led to control of symptoms and slowing of progression in patients with rheumatoid arthritis, reduced rejection rates in transplant patients, and prolonged survival in patients with cancer. The management of immune checkpoint inhibitor treatment in certain challenging patient populations, including patients with pre-existing autoimmune conditions or transplant patients who develop cancer, as well as the management of immunerelated adverse events in patients receiving antitumor therapy, is examined. Finally, the future of immune checkpoint inhibitors, including examples of emerging targets that are currently in development, as well as recent insights gained using new molecular techniques, is discussed. T-cell costimulation and coinhibition play vital roles in these diverse therapeutic areas. Targeting immune checkpoints continues to be a powerful avenue for the development of agents suitable for treating autoimmune diseases and cancers and for improving transplant outcomes. Enhanced collaboration between therapy area specialists to share learnings across disciplines will improve our understanding of the opposing effects of treatments for autoimmune disease/transplant rejection versus cancer on immune checkpoints, which has the potential to lead to improved patient outcomes.
\end{abstract}

\section{Introduction}

An adaptive immune response against invading pathogens is initiated by the activation of naive $\mathrm{T}$ cells, which requires coordinated signals, two of which are fundamental for many aspects of T-cell activation. Signal 1 is stimulatory and involves an antigen/major histocompatibility complex binding to an antigen-specific T-cell receptor (Fig. 1). Signal 2 is mediated by members of the B7 and tumor necrosis factor (TNF) receptor families of cell-surface protein ligands and can be stimulatory or inhibitory $[1,2]$. A third signal of innate cytokines helps $\mathrm{T}$ cells differentiate into protective T-cell subsets required for host immunity [3].

Depending on the affinity, signal 1 can sometimes be effective without the need for a stimulatory signal 2, whereas signal 2 alone cannot lead to activation of T cells [4]. Initially, the CD28 receptor and its counterpart CD80/86 were identified, and it was proposed that T-cell activation occurred following T-cell receptor ligations and assembly of the signaling complex; for example, the binding of CD28 to CD80/86 (Fig. 2) $[2,5,6]$. Subsequent identification of additional B7/CD28 and TNF receptor family members $[2,7,8]$ led to the current understanding that an inhibitory signal 2 can counteract T-cell activation; for example, when cytotoxic T-lymphocyte antigen 4 (CTLA-4; CD152) outcompetes CD28 for B7 binding (Fig. 2). The down-regulation of T-cell responses at immune checkpoints is fine-tuned by many coinhibitory pathways to avoid inappropriate or prolonged activation (Fig. 2) [1,2,9]. The

\footnotetext{
* Corresponding author. Department of Rheumatologic and Immunologic Disease, Cleveland Clinic, 9500 Euclid Avenue, Cleveland, OH, 44195, USA

E-mail address: calabrl@ccf.org (L.H. Calabrese).
} 
regulation of T-cell costimulation (or costimulation modulation) and coinhibition has a function in both health and disease and is at the center of the processes that underpin autoimmunity, transplant rejection, and immune evasion in cancer [2].

Immune checkpoints are essential for maintaining self-tolerance, protecting tissues from damage caused by the immune system, and providing protective immunity [10]. An imbalance in immune homeostasis can lead to costimulation and the upregulation of T-cell activation in autoimmune diseases and transplant rejection [9]. Immune homeostasis is mediated in part by the balance between the costimulatory (e.g. CD28) and coinhibitory (e.g. CTLA-4 or programmed death 1 [PD-1]) signals [9]. CTLA-4 is a checkpoint molecule that is expressed on activated $\mathrm{T}$ cells in the central lymphoid compartment, and has a mainly inhibitory function due to having a higher affinity for $\mathrm{CD} 80 / 86$ than that of CD28 $[1,2,10,11]$. PD-1, another member of the CD28 family of receptors, is expressed primarily on T cells in peripheral tissues, and binds to programmed death ligand 1 or 2 (PD-L1 or PD-L2), which leads to $\mathrm{T}$-cell inhibition [2,10]. Evidence gained from preclinical animal models has provided useful insights into the role of immune checkpoints. In a murine CTLA-4 knockout model, animals developed rapid autoinflammatory responses resulting in fatal lymphoproliferative disease $[12,13]$, whereas in a murine PD-1 knockout model, animals developed lupus-like disease [14].

The role of immune checkpoints has been further elucidated from studies in humans. As the primary costimulation molecule for T-cell activation, loss of expression of CD28 during T-cell maturation can lead to varying T-cell phenotypes (cytotoxic or immunoregulatory) in different disease states, including in inflammatory conditions, infections, cancers, and transplantation [15]. In addition, patients with newly described genetic diseases of CTLA-4 signaling deficiency have heterogeneous symptoms that include aggressive autoimmune manifestations of arthritis, psoriasis, and thrombocytopenia [16]. CTLA-4 haploinsufficiency with autoimmune infiltration (CHAI) is a common variable immunodeficiency-related condition exhibiting a heterozygous loss-of-function mutation in CTLA-4 [16,17]. Patients with CHAI typically develop lymphocytic infiltration of multiple nonlymphoid organs as well as heterogeneous autoimmune symptoms. Patients with LATAIE (LRBA deficiency with autoantibodies, regulatory T-cell defects, autoimmune infiltrations, and enteropathy) have recessive loss-of-function mutations in LRBA, a CTLA-4 trafficking protein, and experience CHAI-like symptoms [16]. The shared mechanism of autoimmunity of these two diseases demonstrates the crucial role of CTLA-4 in immune checkpoint regulation. Single nucleotide polymorphisms in the PD-1 gene that are associated with the risk of developing cancer or autoimmune diseases have been identified, with variation noted between ethnic groups $[18,19]$; such findings may provide further insights into the role of immune checkpoints.

In this article we aim to provide a multidisciplinary perspective on costimulation/coinhibition modulation through the learnings from three diverse therapeutic areas-autoimmunity, transplantation and cancer-and to discuss the future of immune checkpoint therapeutics, including those currently in development. The checkpoint molecules most commonly targeted are CTLA-4 and PD-1/PD-L1; however, emerging targets include T-lymphocyte markers and various T-cell immunoglobulin domains. In addition, the management of immune checkpoint inhibitor treatments in specific and challenging patient populations, including their adverse events, will be reviewed.

\section{The critical function of costimulation/coinhibition modulation and therapeutic targeting of immune checkpoints: perspectives from different therapy areas}

Many immune checkpoints are initiated by ligand-receptor interactions and can readily be blocked by antibodies or modulated by recombinant forms of ligands or their receptors, presenting opportunities for therapeutic targeting. As such, various agents have been investigated, based on increasing costimulatory/coinhibitory pathway knowledge, for controlling unwanted immune responses and enhancing desired immune responses. We summarize here some of the novel immunomodulatory agents (based on the inhibition of receptors and/or ligands of CTLA4 and PD-1/PD-L1) that are currently being used successfully in clinical practice to treat patients with autoimmune diseases, transplant recipients, and patients with cancer (Table 1).

\subsection{In autoimmune diseases}

Autoimmune diseases originate from the breakdown of costimulatory and coinhibitory signals and the loss of self-tolerance due to a shift in immune homeostasis [20]. In rheumatoid arthritis (RA), T-cell activation results in the production of B-cell-derived autoantibodies and macrophage pro-inflammatory cytokines, which leads to inflammation and tissue damage [21-23]. If left unchecked, there is a constant renewal of the T-cell-initiated immune response.

In addition to exacerbation of the costimulatory signal in patients

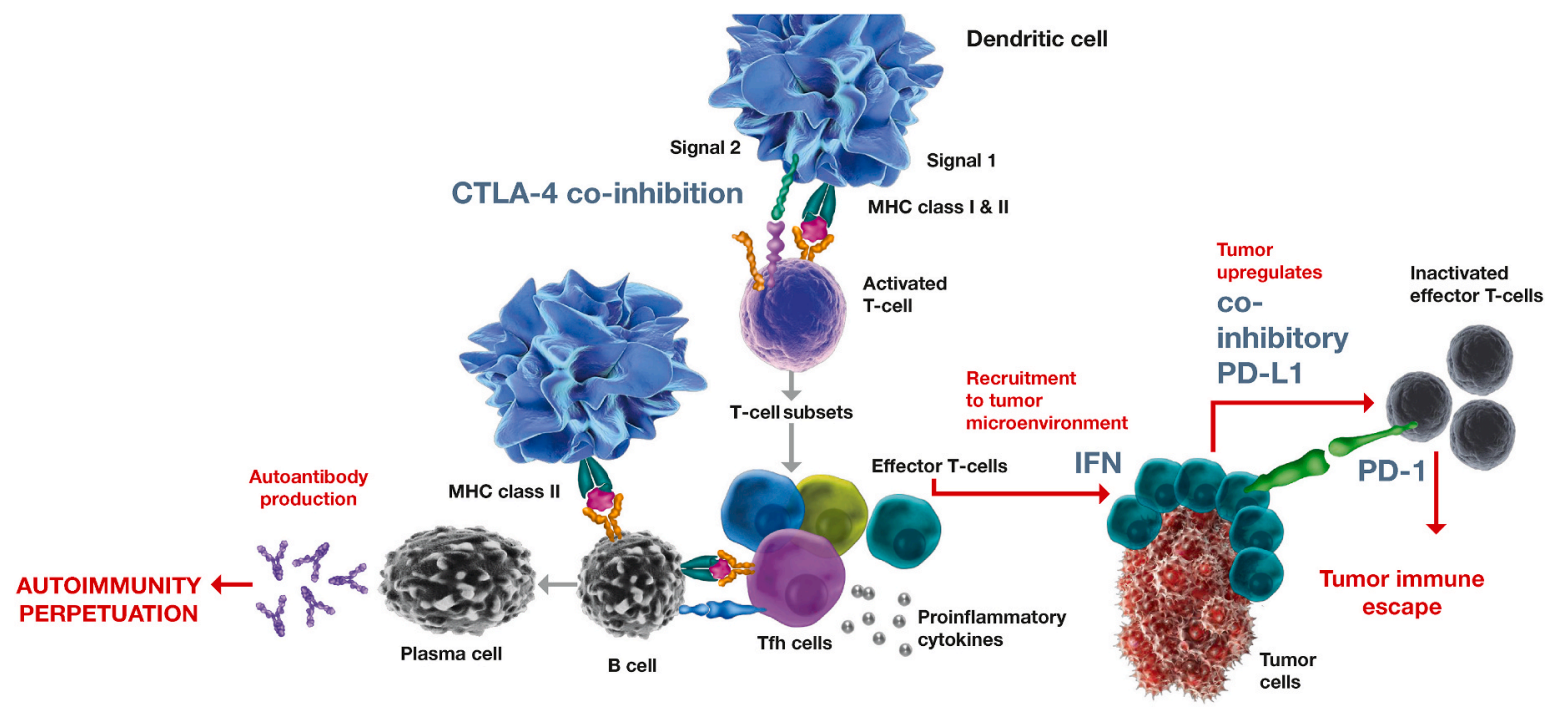

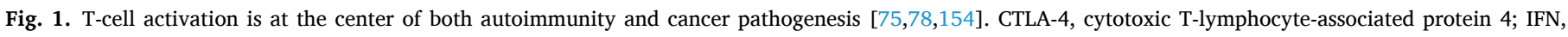
interferon; MHC, major histocompatibility complex; PD-1, programmed death 1; PD-L1, programmed death ligand 1; Tfh, T-follicular helper. 
with RA, studies have noted that levels of CTLA-4 expression in regulatory $\mathrm{T}$ cells are reduced, leading to impaired suppressive capacity of these cells [24]. Other autoimmune diseases that occur due to a shift in immune homeostasis have been investigated, and both CD28 expression and PD-1-expressing T-cell frequency were found to be lower in patients with Sjögren's syndrome and systemic sclerosis [25].

The shift in immune homeostasis via several pathways provides insight into disease development and potential treatment options. Immunomodulation agents used in the treatment of autoimmune diseases act on costimulatory pathways and aim to prevent the overreaction of the immune system. Abatacept, a human CTLA-4 fusion protein, binds to $\mathrm{CD} 80 / 86$, disrupting the continuous cycle of T-cell activation and thereby inhibiting autoantibody and cytokine production, as well as reinstating homeostasis [26,27]. Abatacept is approved in the United States and Europe for treating patients with RA and controls signs and symptoms, slows radiographic disease progression and improves quality of life (QoL) of patients with RA [26,27]. The presence of autoantibodies, in particular anti-citrullinated protein antibodies (ACPAs), are characteristic of RA and may be present years before the patient exhibits any symptoms [28]. ACPAs are associated with more aggressive disease, increased disease activity, structural damage including bone loss and erosion and functional impairment [28-32]. The presence of ACPAs may also be associated with a lower likelihood of achieving and maintaining drug-free remission following treatment with methotrexate (MTX) or biological disease-modifying antirheumatic drugs (DMARDs) [27,33]. An exploratory analysis of a Phase III study has shown that efficacy of abatacept treatment was greater in patients with higher baseline ACPA levels than in those with lower levels ( $\mathrm{p}=$ 0.003) [34]. Furthermore, in an observational study, only treatment with the DMARDs that target the adaptive immune response, such as abatacept and rituximab, resulted in significant decreases in ACPA levels; in addition, only abatacept preserved immunoglobulin G (IgG) levels [35]. It has also been reported in another post hoc evaluation of a Phase III study that treatment with abatacept and MTX improved the probability of rheumatoid factor (RF) and ACPA seroconversion over MTX alone [36]. Additionally, patients who seroconverted from ACPA + to ACPA- status had better clinical and radiographic outcomes [36]. Real-world data have also shown that abatacept initiators achieve significant differences in low disease activity and remission based on their ACPA/RF status, with patients who have positive status exhibiting improved clinical response [37].
Table 1

Summary of immune checkpoint targets and approved therapeutic agents.

\begin{tabular}{|c|c|c|}
\hline Target & $\begin{array}{l}\text { Therapeutic } \\
\text { agent }\end{array}$ & Stage of development (as of September 2019) \\
\hline \multirow[t]{2}{*}{$\begin{array}{l}\text { CD80/ } \\
86\end{array}$} & Abatacept & $\begin{array}{l}\text { Approved by FDA for treatment of RA (2005), } \\
\text { polyarticular juvenile idiopathic arthritis (2008), } \\
\text { and psoriatic arthritis (2017) }\end{array}$ \\
\hline & Belatacept & $\begin{array}{l}\text { Approved by FDA for immune suppressive } \\
\text { treatment of kidney transplant patients (2011) }\end{array}$ \\
\hline CTLA-4 & Ipilimumab & $\begin{array}{l}\text { Approved by FDA for treatment of metastatic } \\
\text { melanoma (2011) }\end{array}$ \\
\hline \multirow[t]{6}{*}{$\begin{array}{l}\text { PD-1/ } \\
\text { PD-L1 }\end{array}$} & Pembrolizumab & $\begin{array}{l}\text { Approved by FDA for treatment of metastatic } \\
\text { melanoma (2014), NSCLC (2015), HNSCC (2016), } \\
\text { Hodgkin lymphoma (2017), urothelial carcinoma } \\
\text { (2017), solid tumors (2017), gastric cancer (2017), } \\
\text { cervical cancer (2018), large B cell lymphoma } \\
\text { (2018), and hepatocarcinoma (2018) }\end{array}$ \\
\hline & Nivolumab & $\begin{array}{l}\text { Approved by FDA for treatment of metastatic } \\
\text { melanoma (2014), NSCLC (2015), RCC (2015), } \\
\text { Hodgkin lymphoma (2017), HNSCC (2016), } \\
\text { urothelial carcinoma (2017), colorectal cancer } \\
\text { (2017), and hepatocarcinoma (2017) }\end{array}$ \\
\hline & Atezolizumab & $\begin{array}{l}\text { Approved by FDA for treatment of urothelial } \\
\text { carcinoma (2016), metastatic lung cancer (2016), } \\
\text { bladder cancer (2017), and nonsquamous NSCLC } \\
\text { (2018) }\end{array}$ \\
\hline & Avelumab & $\begin{array}{l}\text { Approved by FDA for treatment of metastatic } \\
\text { Merkel cell carcinoma (2017) and locally advanced } \\
\text { or metastatic urothelial carcinoma (2017) }\end{array}$ \\
\hline & Durvalumab & $\begin{array}{l}\text { Approved by FDA for treatment of urothelial } \\
\text { carcinoma (2017) and NSCLC (2018) }\end{array}$ \\
\hline & $\begin{array}{l}\text { Cemiplimab- } \\
\text { rwlc }\end{array}$ & $\begin{array}{l}\text { Approved by FDA for treatment of metastatic } \\
\text { cutaneous squamous cell carcinoma (2018) }\end{array}$ \\
\hline
\end{tabular}

CTLA-4, cytotoxic T-lymphocyte antigen 4; FDA, United States Food and Drug Administration; HNSCC, head and neck squamous cell carcinoma; NSCLC, nonsmall cell lung cancer; PD-1, programmed-death 1; PD-L1, programmed death ligand 1; RA, rheumatoid arthritis; RCC, renal cell carcinoma.

As many immune checkpoints can be readily blocked by antibodies, additional therapeutic targeting opportunities could be investigated for RA and other autoimmune diseases. A defective PD-1 immune checkpoint has been characterized as early as at the undifferentiated stage of RA [38]. This means that, despite the increased expression of PD-1 in synovial tissue of patients with RA, the PD-1 pathway is down-regulated during disease progression [38]. Recently, Guo et al. suggested that an agonistic PD-1 antibody agent may, in the future, show efficacy and

\section{Co-stimulation}

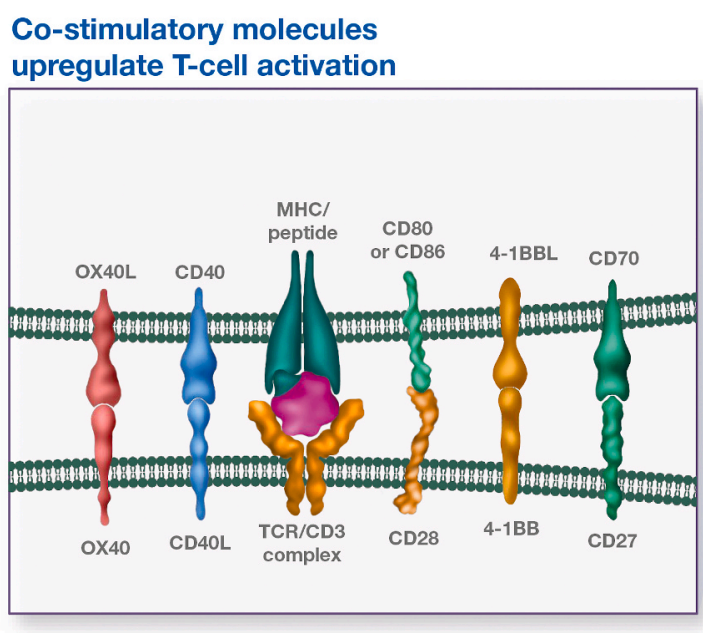

\section{Co-inhibition}

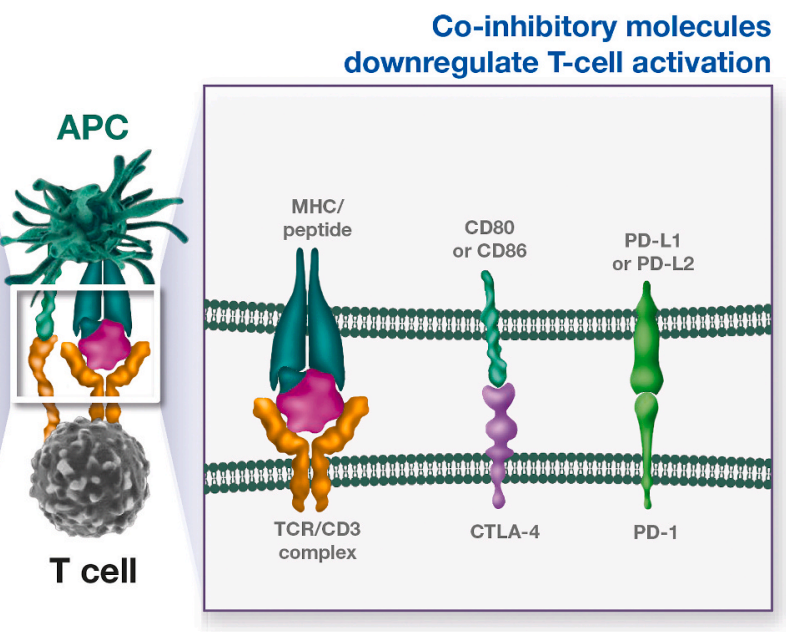

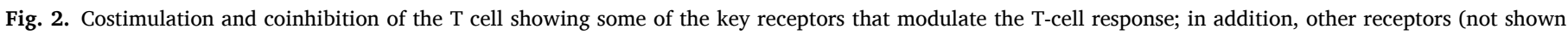


complex; PD-1, programmed death 1; PD-L1/2, programmed death ligand 1/2; TCR, T-cell receptor. 
prevent progression of RA by restoring the inhibitory activity of PD-1 [38].

Immunomodulation agents have been investigated for use in other autoimmune diseases such as Sjögren's syndrome and systemic sclerosis [39-42]. An experimental anti-CD86 monoclonal antibody prevented autoimmune lesions in a murine Sjögren's syndrome model [42]. In patients with Sjögren's syndrome, abatacept has been shown to reduce disease activity [41]. For human fibrotic diseases such as systemic sclerosis, CD40/154 (CD40L) signal blockade may be a therapeutic option [40]. Murine models have shown that abatacept prevented and induced regression of inflammation-driven dermal fibrosis [39], and this treatment strategy is currently under investigation in a Phase II clinical trial assessing the efficacy of abatacept to improve skin involvement in patients with early diffuse systemic sclerosis (NCT02161406).

\subsection{In transplantation}

The disciplines of solid organ and hematopoietic stem cell transplantation (HSCT) have advanced greatly over the past 50 years. Solid organ transplantation is the standard treatment for improving both the QoL and survival of patients with various end-stage organ diseases [43]. In HSCT, the infusion of stem cells can help restore hematopoietic function as part of treatment for patients with certain cancers, such as multiple myeloma or leukemia [44]. In the United States, more than 36, 000 patients received solid organ transplants [45], and more than 8000 patients underwent allogeneic (donor) HSCT [36,46] in 2018.

Despite their benefits, serious immune reactions, such as transplant rejection and graft-vs-host disease (GVHD), can complicate solid organ transplantation and HSCT, respectively [43]. Rejection is an immune response leading to damage of transplanted tissues. This response results from an intricate sequence of interactions which involves both innate and adaptive immune systems, including a key role of T cells [47]. The process is initiated by recognition of donor-derived antigens by recipient $\mathrm{T}$ cells (allorecognition). In direct allorecognition, T-cell-mediated reactions driven by CD4 $\mathrm{T}$ cells are focused on donor human leukocyte antigen (HLA) class II antigen mismatches, while cytotoxic CD8 T cells drive responses specific for HLA class I (A, B, or C) antigens [47]. Indirect allorecognition involves the presentation of processed alloantigen epitopes, and follows a more CD4 T-cell driven activation of donor-specific CD8 $\mathrm{T}$ cells [48]. The development of de novo donor-specific antibodies (alloimmune response) is also CD4 T-cell dependent and is associated with accelerated graft loss in solid organ transplant recipients due to direct effector functions of the allospecific antibodies acting on the graft and development of allospecific T cells $[47,49]$. All of the CD4 T-cell-dependent responses are heavily influenced by costimulatory signals. The widespread use of potent immunosuppressive drugs-for example, calcineurin inhibitors-has decreased early graft loss due to rejection [47]. However, prolonged treatment with a maintenance regimen that includes 1-3 immunosuppressants often results in infections [47], attributed to the non-antigen-specific effects of the drugs used, and numerous off-target toxicities, particularly nephrotoxicity of calcineurin inhibitors [50]. For this reason, T-cell costimulation has been recognized as a highly effective approach for preventing alloantibody formation.

In HSCT, HLA-matched sibling donors are only found for approximately $30 \%$ of patients, and such limited availability of matched donors has led to an increase in the use of mismatched, unrelated donors [51]. Unfortunately, acute GVHD, which is associated with high mortality rates, occurs more frequently in mismatched transplantation than with matched donors [47,52]. Studies of in vivo T-cell costimulation blockade to prevent acute GVHD have identified several potential T-cell costimulation pathway targets $[53,54]$.

Approaches targeting T-cell costimulation have been investigated, both for preventing rejection and in the prevention and treatment of acute GVHD. In transplantation, therapeutic agents that act on costimulatory pathways and prevent the rejection process while preserving the protective function of the immune system are required [47,55]. Belatacept, a second-generation T-cell modulator, was genetically engineered to increase binding affinity to CD80/86 [56,57], and is approved in the United States and Europe for immune-suppressive treatment in kidney transplant patients. Prevention of CD80/86 binding to CD28 is an approach referred to as "costimulatory blockade" and is effective in preventing allograft rejection in rodent models [58]. However, in primate preclinical models, monotherapy is generally not effective and adjuvant therapies are required [59,60]. Effective adjuvants included other costimulatory pathway inhibitors, particularly CD40/CD154 (CD40L) blockade, and mechanistic target of rapamycin inhibitors (for example, sirolimus) [60,61]. Phase III trials of belatacept in adult kidney transplant patients demonstrated non-inferiority to cyclosporine and improvement in long-term renal function with belatacept $[62,63]$. A post hoc analysis showed that patients treated with belatacept were significantly less likely to develop de novo donor-specific antibodies over time $(\mathrm{p}<0.01)$ than those treated with cyclosporine [62]. However, in transplantation, it has also been reported that belatacept treatment is associated with an increased risk of cytomegalovirus (CMV) primary infection and a prolonged course of viral replication in CMV high-risk patients [64]. This suggests that new viral exposure encountered at the time of transplantation (when the dose of adjuvant immunosuppressant is high) is likely to precipitate a heightened risk of viremia and clinical viral illness.

In general, costimulation blockade is most effective for naive responses; as T cells gain antigen experience, the approach can become less effective and may, in fact, be largely ineffective for established Tcell memory [65]. However, an immune memory that results from pathogen exposure and induces costimulation resistance can occur even in recipients who have not had direct exposure to a donor antigen [65]. As such, costimulation-blockade-resistant rejection can be present even in allo-naive individuals [66]. Combination therapy can help overcome this; for example, alemtuzumab (a humanized IgG1 anti-CD52 monoclonal antibody) can eliminate costimulation-blockade-resistant rejection, and belatacept prevents alloantibody production promoted by alemtuzumab [67-70]. Following alemtuzumab treatment, more CD28 ${ }^{+}$ naive $\mathrm{T}$ cells are produced that are easier to control with costimulation blockade [67].

With the challenges of targeting CD80/86, the limited success in downregulating alloimmunity and the untoward immune-activating effects, there is a growing interest in selectively targeting CD28 [71]. Results from a study in non-human primates with an investigational, therapeutic, anti-CD28 antigen-binding fragment highlighted the need for the risks, including comprehensive down-modulation of T-cell activation, to be fully assessed before deploying a CD28-targeted agent [71].

In patients with leukemia, abatacept treatment was associated with a marked reduction in the cumulative incidence of acute GVHD (grade III-IV) and reduced mortality compared with a historical cohort [72]; further study has shown that patients treated with abatacept did not have a greater risk of relapse [72]. In addition, CTLA-4-Ig has been shown to prevent GVHD in animal models, both when given to the recipient and when used ex vivo in the infused bone marrow product [73].

\subsection{In cancer}

Global rates of cancer incidence and mortality are rapidly increasing, due in part to both longer life expectancy and population growth. In 2018 there were an estimated 18.1 million new cancer cases and 9.6 million cancer deaths [74]. Malignant tumors can circumvent both innate and adaptive immune responses and develop in an immunosuppressive microenvironment, achieved through inhibition of effector T-cell function or recruitment of regulatory immune cells to evade immune response [10,75-77]. As such, in patients with cancer, an antitumor response is avoided due to an under-reaction of the immune system. This is in contrast to the over-reaction that occurs in patients 
with autoimmune disease or following transplantation (Fig. 1) [75,78, 79], and highlights the importance of maintaining the balance between comodulatory signals for immune homeostasis.

The use of immune checkpoint blockade therapy has significantly prolonged the survival of some patients with cancer. For example, CTLA4 blocking antibody treatment leads to prolonged T-cell activation and T-cell proliferation/diversity, as well as increases in patients' capacity to produce an effective immune response $[78,80]$. Ipilimumab (CTLA-4-blocking antibody), approved for the treatment of melanoma, has been shown to augment T-cell activation and proliferation, including tumor-infiltrating $\mathrm{T}$ effector cells [81]. In a study of patients with melanoma treated with ipilimumab, tumor antigen-specific $\mathrm{T}$ cells with specificities in the blood of clinically responsive patients were noted that were not present before treatment; these cells were not seen in clinically nonresponsive patients [82]. Thus, CTLA-4 suppresses T cells within the lymphoid compartment rather than within the tumor microenvironment by limiting T-cell proliferation, thus preventing expansion of antitumor T-cell responses [83].

PD-1 and PD-L1 inhibitors increase T-cell activity against tumor cells by blocking negative regulatory signals mediated by $\mathrm{PD}-1$, i.e. restoring antitumor response. PD-L1 expression is a marker of improved response to treatment with PD-1 or PD-L1 inhibitors and clinical outcome in some, but not all, patients [10,78]. A recent meta-analysis [84] found that PD-L1 expression was prognostic for objective response rate but not overall survival in patients with metastatic urothelial cancer. The approved therapies nivolumab and pembrolizumab, and the investigational therapy spartalizumab (currently in Phase III trials; NCT02967692), are human IgG4 monoclonal antibodies that bind to the PD-1 receptor, while the approved immune checkpoint inhibitors avelumab, atezolizumab and durvalumab block PD-L1 [85]. Immune checkpoint combination therapies including ipilimumab have recently been evaluated for treatment of renal cell carcinoma, providing significant improvements in survival benefit [86,87]. In addition, current Phase II and III checkpoint inhibitor trials include use of nivolumab as monotherapy (NCT03063450), or in combination with ipilimumab (NCT03469960, dual checkpoint blockade), relatlimab (anti-lymphocyte activation gene 3 [LAG-3], NCT03743766, dual checkpoint blockade), or NKTR-214 (NCT02983045, coinhibition and cytokine to target CD122 [signal 3]).

As there are multiple factors in the tumor microenvironment that inhibit T-cell effector functions, blocking two or more negative checkpoints can lead to increased therapeutic efficacy (e.g. CTLA-4 plus PDL1) [79]. In support of this, the therapeutic combination of ipilimumab (CTLA-4) and nivolumab (PD-1) has recently been shown to improve overall survival rates in patients with advanced melanoma [88]. The use of combined nivolumab and ipilimumab in patients with renal cell carcinoma in a Phase III study demonstrated significantly higher overall survival and objective response rates than with sunitinib, a multi-targeted receptor tyrosine kinase inhibitor [89]. Combined nivolumab and ipilimumab also showed efficacy in a Phase III trial in lung cancer [90].

Although broadening the repertoire of $\mathrm{T}$ cells may allow better recognition of antigens, particularly neoantigens [91,92], it may also lead to unwanted adverse events via activation of non-specific pathways; for example, decreased peripheral tolerance (PD-1 inhibition) [93] or diversification of the T-cell repertoire toward cross-reactive $\mathrm{T}$ cells (CTLA-4 blockade) [12,94]. In patients with metastatic, castrate-resistant prostate cancer it was noted that ipilimumab induced greater diversification in the T-cell repertoire of those with immune-related adverse events (irAEs) compared with those without [80]. As a result of the unbalancing of the immune system, irAEs can affect any tissue, but mostly the skin, gastrointestinal, pulmonary, hepatic, and endocrine glands are associated with checkpoint therapy [9, 95,96]. Numerous irAEs have been recorded, including colitis and psoriasis. In addition, mild musculoskeletal events such as arthralgia, myalgia, arthritis, and sicca symptoms are commonly reported
[97-100].

Due to their clinical efficacy, the numbers of patients receiving checkpoint inhibitors is increasing [96]. A key question is whether any or all of these irAEs represent the new occurrence of idiopathic forms of autoimmunity derived from similar immunopathogenic pathways, or alternatively new and undescribed examples of autoinflammatory or autoimmune diseases [101]. As such, the pathogenesis of irAEs is incompletely understood and numerous immunologic hypotheses exist to explain their evolution [102]. These include (a) disease occurring via generalized immune activation and elaboration of inflammatory cytokines, (b) off-target effects of the checkpoint inhibitors on targeted ligand-expressing host tissues, and (c) the exacerbation of pre-existing asymptomatic autoimmunity (i.e. patients with asymptomatic ACPAs developing RA and euglycemic patients with anti-islet cell antibodies developing Type 1 diabetes) [102]. Finally, another theory with some limited evidence relates to off-target effects of newly-sensitized T cells thought to be due to tumor cell death, and the subsequent release of both tumor and self-antigens [102]. The resulting self-reactive T cells cause additional tumor destruction and off-target destruction of normal tissue, leading to autoimmunity [97]. A recent review [103] suggested that the similarity between irAEs and autoimmune disorders supports the hypothesis that irAEs may be linked to genetic susceptibility loci related to various autoimmune diseases. From a review of the literature, groups of susceptibility loci were identified that are most likely associated with irAEs, and which could be used in the future to predict irAEs and help to identify patients who may develop them [103]. The authors hypothesized that the environmental component, checkpoint inhibition therapy, may trigger underlying inflammatory disease in genetically predisposed individuals [103].

\section{Management of immune checkpoint inhibitor treatments in specific patient populations and their adverse events}

As use of immune checkpoint inhibitor treatment increases, additional factors will need to be taken into account regarding specific patient populations. Particular consideration will be needed prior to initiating immune checkpoint therapy with respect to any pre-existing autoimmune conditions, as well as for treatment of tumors in transplant patients. The most viable options for treating irAEs also need to be carefully considered, and algorithms that include escalation with immune suppressive drugs have been used for treatment of the consequences of irAEs [98,104-106]. It should be noted that even though irAEs show similar symptoms to autoimmune phenomena, their rapid onset and reversibility following prompt initiation of immune suppression therapy differentiates them from actual autoimmune diseases. In addition, although not fully addressed in this review, the potential for diminished cancer immune control in immune checkpoint treatment of autoimmune disease or transplant rejection needs further study.

\subsection{Patients with autoimmune disease who develop cancer}

The overall risk of cancer among patients with RA initiating abatacept treatment does not differ substantially from that of conventional synthetic DMARD- or placebo-treated patients with RA [107,108]. The management of cancer in patients with autoimmune disease can be problematic, as use of biologic agents to treat their current autoimmune disease may impact their immune checkpoint inhibitor cancer treatment [109]. Limited information is available regarding this group of patients as those with pre-existing conditions are often excluded from clinical trials of immune checkpoint inhibitors [98,110-112]. However, immune checkpoint inhibitors can precipitate a flare in the autoimmune disease of some patients with pre-existing conditions, which may be manageable with corticosteroids [98,99,105]. Health insurance data suggested that having a pre-existing autoimmune disease was associated with a modest increase in hospitalizations with irAE diagnoses and with corticosteroid treatment [113]. Findings from a systematic review 
suggested that flares and irAEs can be successfully managed without discontinuing therapy, although occasionally events with some agents may be severe and fatal [114].

Studies are required to evaluate risk-benefit ratios and the decision to initiate checkpoint inhibitor therapy should be a multidisciplinary one, with close monitoring and careful consideration of the severity of the underlying autoimmunity, prognosis of cancer, alternative options, and patients' preferences. A study is currently underway assessing tolerance in patients with pre-existing autoimmune conditions who received immune checkpoint inhibitors for an advanced cancer in clinical practice (NCT03140137).

\subsection{Transplant patients who develop cancer}

Compared with the general population, transplant recipients have an increased cancer risk [115]. In kidney transplantation patients, overall rates of malignancy were similar between belatacept- and cyclosporine-treated groups [63]. Although data are limited, the use of immune checkpoint blockade for tumors in transplant patients is warranted [116,117]. Organ transplant recipients are generally excluded from checkpoint inhibitor clinical studies; however, it has been suggested that transplant patients can be treated with checkpoint inhibitors and obtain a durable antitumor immune response while avoiding rejection [117]. As immune checkpoint inhibitors carry a high risk of graft rejection, they should be used with caution and in a multidisciplinary setting $[118,119]$. A current Phase I trial investigating tacrolimus, nivolumab, and ipilimumab in treating kidney transplant recipients with cancer is ongoing (NCT03816332).

\subsection{Patients who develop musculoskeletal irAEs}

Managing irAEs while allowing effective antitumor therapy is challenging [120]. Numerous irAEs have been recorded [95,121]. Currently, no algorithms exist for the treatment of commonly reported musculoskeletal irAEs. Based on algorithms for other irAEs, it has been suggested that treatment should be based on symptom severity and functional consequences $[98,99,104,105]$. Non-steroidal anti-inflammatory drugs and low-dose corticosteroids can be used for patients with less severe symptoms, and increased corticosteroid doses or TNF inhibitors for those with more severe symptoms [99,102,104,105,122-124]. However, prolonged use of TNF inhibitors may lead to significant immunosuppression and can negatively impact the antitumor efficacy of immune checkpoint therapy; in these cases, an anti-interleukin (IL)-6 receptor antibody may be an effective alternative.

\section{Ongoing research and developments in T-cell modulation}

Currently, the checkpoint molecules most commonly targeted are CTLA-4 and PD-1/PD-L1 (Table 1), and agents blocking these pathways have demonstrated durable clinical activity in transplant recipients, in patients with autoimmune diseases, and in multiple cancer types. Although a meta-analysis highlighted the clinical differences in safety among immune checkpoint inhibitors for patients with cancer, head-tohead efficacy data are currently limited and hypotheses regarding relative efficacies are speculative [125].

In addition, checkpoint inhibitors may have significant potential for future use for treating chronic infections or sepsis; however, further studies are needed to confirm their role [126-130]. Pembrolizumab may help patients with progressive multifocal leukoencephalopathy, an opportunistic viral infection predominantly seen in immunosuppressed patients (most commonly in HIV cases, lymphoproliferative disorders, and primary immunodeficiency), by blocking the PD-1 receptor to increase the cellular immune response $[127,128,131]$.

Some subsets of patients with cancer treated with checkpoint inhibitors do not respond, which may be due in part to a lack of sufficient infiltration by tumor-reactive and -infiltrating lymphocytes [132,133].
The identification of biomarkers predictive of response to checkpoint inhibitors is an aspirational area that requires further investigation [134]. CD8 ${ }^{+}$T-effector cell phenotype was linked to good response in patients with metastatic urothelial cancer [135], whereas TGF $\beta$ signaling in the tumor microenvironment was a determinant of poor response to PD-1/PD-L1 blockade [135,136]. In transplant patients, various potential markers for belatacept resistance have been noted, namely CD57 expression [65], CD2hi [137], and pretransplant frequencies of $\mathrm{CD}_{2} 8^{+} \mathrm{CD} 4^{+}$TEM cells [138].

Further understanding of the mechanism of action of checkpoint inhibitors will aid the design of forthcoming therapies. Consequently, research is focusing on the identification of new entities that may enhance checkpoint inhibitor response rates in patients with cancer, and several new inhibitory pathways are under preclinical and early clinical investigation (Table 2) [132,139,140]. Emerging targets include T-lymphocyte markers, such as LAG-3 T-cell immunoglobulin- and mucin-domain-containing molecule 3 (TIM-3), V-domain containing Ig suppressor of T-cell activation (VISTA), T-cell immunoglobulin and ITIM domain (TIGIT), and B7-H3. LAG-3 and PD-1 are frequently co-expressed and upregulated on tumor-infiltrating lymphocytes, leading to immune exhaustion and tumor growth [132]. TIM-3 is a direct negative regulator of $\mathrm{T}$ cells that is expressed on natural killer (NK) cells and macrophages and indirectly promotes immunosuppression [132]. Particularly elevated TIM-3 levels are noted on dysfunctional and exhausted T cells, suggesting an important role in malignancy [141]. TIGIT is a CD28 receptor that is expressed by NK and T cells whereas VISTA acts as a stimulatory and negative ligand [132].

More informed and effective therapeutic strategies may be possible with an improved understanding of the anti-tumor $\mathrm{CD}^{+} \mathrm{T}$-cell response after checkpoint blockade. In preclinical models, bulk and single-cell RNA profiles of $\mathrm{CD}^{+}$tumor infiltration lymphocytes after combined TIM-3+PD-1 blockade revealed significant changes in the transcriptional profile of PD-1 tumor-infiltrating $\mathrm{T}$ cells [142]. In addition, anti-PD-1 was observed to act on a specific subpopulation of exhausted $\mathrm{CD}^{+}$tumor infiltrating lymphocytes that differentially mediated tumor control and responded to checkpoint blockade [143]. In a small cohort of patients with non-small cell lung cancer treated with PD-1 blockade, the presence of T-lymphocyte populations with high PD-1 tumor-infiltrating lymphocytes was strongly predictive for both response and survival [144]. The mechanism of action of anti-PD-1 therapy was further studied in a comprehensive genomic analysis of melanoma samples pre- and post-nivolumab therapy, which found an association of pre-therapy tumor mutation load and clonal mutation load with survival

Table 2

Ongoing Phase II clinical trials of non-CTLA4 and non-PD-1 immune checkpoint inhibitors.

\begin{tabular}{lll}
\hline Target & Therapeutic agent & Condition (study number) \\
\hline TIM-3 & BGB-A425 & Advanced solid tumors (NCT03744468) \\
& MBG453 & Advanced solid tumors (NCT02608268) \\
LAG-3 & Relatlimab (and nivolumab) & Metastatic melanoma (NCT03743766 \\
& (BMS986213) & and NCT02519322) \\
& & Gastric or gastroesophageal junction \\
& cancer (NCT03662659) \\
& & Esophagogastric cancer (NCT03610711) \\
& & Solid tumors (NCT03459222) \\
& Relatlimab (BMS986016) & B-cell malignancies (NCT02061761) \\
& Eftilagimod alpha & Metastatic NSCLC and HNSCC \\
& & (NCT03625323) \\
& & Breast cancer (NCT02614833) \\
& BAG525 & Breast cancer (NCT03499899) \\
CDSCLC and metastatic melanoma \\
\end{tabular}

CTLA-4, cytotoxic T-lymphocyte antigen 4; HNSCC, head and neck squamous cell carcinoma; LAG-3, lymphocyte activation gene 3; NSCLC, non-small cell lung cancer; PD-1, programmed-death 1; TIM-3, T-cell immunoglobulin- and mucin-domain-containing molecule 3. 
and response [145]. This analysis revealed the changing transcriptional and microenvironmental alterations induced by anti-PD-1 therapy, and identified a broad spectrum of immune checkpoint-related genes that were upregulated.

Furthermore, agonists of stimulatory checkpoint pathways such as OX40, inducible T-cell co-stimulator (ICOS/ICOS-L), CD27/CD70 and glucocorticoid-induced TNF receptor, 4-1BB, CD40, or molecules targeting tumor microenvironment components like IDO or TLR are being assessed [132]. A Phase I study evaluating mRNAs encoding for human OX40L, IL-23, and IL-36 $\gamma$ in combination with durvalumab is ongoing (NCT03739931). The NK cell marker CD94/NKG2A and the killer immunoglobulin-like receptor family are also under investigation [132, 146].

While checkpoint inhibitors induce durable responses in patients with a variety of cancers, combinations of agents have shown enhanced potency, and combining inhibitors with a costimulatory agent has also improved outcomes. In addition to affecting $\mathrm{T}$ cells, inhibitors can also augment NK cell function [147]. Identifying the molecular and cellular factors required for maintaining an immunosuppressive tumor microenvironment will drive the successful development of novel NK cell-based immunotherapies. Therefore, combinations of checkpoint inhibitors with other treatments are being evaluated, such as combining PD-1 pathway inhibitors with recombinant cytokines and neoantigen-based cancer vaccines [148]. The safety and tolerability of new IL-2 inhibitors, for example NKTR-214, IL-15 super agonist, and PEGylated IL-10, have been investigated in early phase clinical trials [148]. In a study it was noted that IL-12, a pro-inflammatory and pro-stimulatory cytokine, improves the tumor immune microenvironment [149].

From the studies described, it can be seen that malignancy is the focus of many trials; however, research is also ongoing in autoimmune diseases and transplantation. An analysis of gene signatures in synovial tissue from patients at various stages of RA development suggested that the use of agonistic PD-1 antibody-based therapeutics may show efficacy in RA treatment [38]. In addition, a Phase II trial has recently assessed the efficacy and safety of a novel anti-CD28 domain antagonist antibody (lulizumab pegol) in patients with systemic lupus erythematosus (NCT02265744) [150]. Development of novel agents targeting other costimulatory molecules including ICOS/ICOS-L, PD-1/PD-L1, and CD40/CD154 have shown early promise for transplantation patients [151]. Although previously several clinical trials evaluating the safety and efficacy of anti-CD154 agents had to be stopped prematurely due to the occurrence of severe thromboembolic complications in some patients [152], different strategies for addressing this issue are being evaluated.

Another novel approach being investigated is the use of small molecule protein-protein interaction inhibition. For example, RhuDex targeting CD80/28 and CA-170 targeting PD-1-PD-L1 are being investigated, which may have improved safety profiles with less immunogenic effects than currently available immune checkpoint inhibitors [153].

\section{Conclusions}

T-cell costimulation, T-cell coinhibition and T-cell-B-cell communication all play vital roles in the pathophysiology of autoimmune diseases and cancer, and in the prevention of transplant rejection. As such, targeting the immune checkpoint continues to be a powerful avenue for the development of agents suitable for treating autoimmune diseases and cancers, and for improving transplant outcomes. Immune checkpoint targeting can lead to control of autoimmunity via costimulation modulation in autoimmune disease and transplantation, and antitumor response via blocking of coinhibitory molecules in cancer. With the increasing development of checkpoint therapy, fostering enhanced collaboration between rheumatologists, oncologists, and transplant specialists will deepen our understanding of the diametric effects of immune checkpoint inhibitors as treatment for autoimmune disease/ transplant rejection versus cancer along with collective knowledge of their associated irAEs and potentially improve patient outcomes across diverse therapy areas.

\section{Funding}

This work did not receive any specific grant from funding agencies in the public, commercial, or not-for-profit sectors.

\section{Declaration of competing interest}

LHC acted as a consultant for Amgen, AbbVie, Bristol Myers Squibb , Crescendo, Genentech, Gilead, GlaxoSmithKline, Horizon, Janssen, Lilly, Pfizer, Regeneron, Sanofi-Genzyme, and UCB; and acted as a speaker for AbbVie, Bristol Myers Squibb , Celgene, Genentech, Horizon, Janssen, Lilly, Regeneron, and Sanofi. RC received speaker and advisory fees from AbbVie, Bristol Myers Squibb , Celgene, Eli Lilly, Gilead, Janssen, Merck Sharp \& Dohme, Novartis, Pfizer, Roche, Sanofi, and UCB. CUB acted as an advisor for AstraZeneca, Bristol Myers Squibb , Genmab, GlaxoSmithKline, Lilly, Merck Sharp \& Dohme, Novartis, Pfizer, Pierre Fabre, and Roche; received research funding from Bristol Myers Squibb , NanoString, and Novartis; and owns stock in Forty Seven, Neon Therapeutics, and Uniti Cars. ADK: received grant support from Bristol Myers Squibb .

\section{Acknowledgments}

Professional medical writing and editorial assistance was provided by Fiona Boswell, PhD, and Joanna Wright, DPhil, at Caudex and was funded by Bristol Myers Squibb.

\section{References}

[1] A.K. Abbas, A.H. Lichtman, S. Pallai, Activation of T Lymphocytes. Cellular and Molecular Immunology, Elsevier Saunders, Philadelphia, PA, 2015, pp. 199-212.

[2] G. Bakdash, S.P. Sittig, T. van Dijk, C.G. Figdor, I.J. de Vries, The nature of activatory and tolerogenic dendritic cell-derived signal II, Front. Immunol. 4 (2013) 53.

[3] A. Jain, C. Pasare, Innate control of adaptive immunity: beyond the three-signal paradigm, J. Immunol. 198 (2017) 3791-3800.

[4] C. Dubey, M. Croft, S.L. Swain, Naive and effector CD4 T cells differ in their requirements for T cell receptor versus costimulatory signals, J. Immunol. 157 (1996) 3280-3289.

[5] M. Azuma, D. Ito, H. Yagita, K. Okumura, J.H. Phillips, L.L. Lanier, et al., B70 antigen is a second ligand for CTLA-4 and CD28, Nature 366 (1993) 76-79.

[6] P.S. Linsley, E.A. Clark, J.A. Ledbetter, T-cell antigen CD28 mediates adhesion with B cells by interacting with activation antigen B7/BB-1, Proc. Natl. Acad. Sci. U. S. A. 87 (1990) 5031-5035.

[7] P.S. Linsley, W. Brady, M. Urnes, L.S. Grosmaire, N.K. Damle, J.A. Ledbetter CTLA-4 is a second receptor for the B cell activation antigen B7, J. Exp. Med. 174 (1991) 561-569.

[8] R.M. Locksley, N. Killeen, M.J. Lenardo, The TNF and TNF receptor superfamilies: integrating mammalian biology, Cell 104 (2001) 487-501.

[9] L. Calabrese, V. Velcheti, Checkpoint immunotherapy: good for cancer therapy, bad for rheumatic diseases, Ann. Rheum. Dis. 76 (2017) 1-3.

[10] D.M. Pardoll, The blockade of immune checkpoints in cancer immunotherapy, Nat. Rev. Canc. 12 (2012) 252-264.

[11] N. Beyersdorf, T. Kerkau, T. Hunig, CD28 co-stimulation in T-cell homeostasis: a recent perspective, ImmunoTargets Ther. 4 (2015) 111-122.

[12] E.A. Tivol, F. Borriello, A.N. Schweitzer, W.P. Lynch, J.A. Bluestone, A.H. Sharpe, Loss of CTLA-4 leads to massive lymphoproliferation and fatal multiorgan tissue destruction, revealing a critical negative regulatory role of CTLA-4, Immunity 3 (1995) 541-547.

[13] C.A. Chambers, T.J. Sullivan, J.P. Allison, Lymphoproliferation in CTLA-4deficient mice is mediated by costimulation-dependent activation of CD4+ T cells, Immunity 7 (1997) 885-895.

[14] H. Nishimura, M. Nose, H. Hiai, N. Minato, T. Honjo, Development of lupus-like autoimmune diseases by disruption of the PD-1 gene encoding an ITIM motifcarrying immunoreceptor, Immunity 11 (1999) 141-151.

[15] D. Mou, J. Espinosa, D.J. Lo, A.D. Kirk, CD28 negative T cells: is their loss our gain? Am. J. Transplant. 14 (2014) 2460-2466.

[16] B. Lo, J.M. Fritz, H.C. Su, G. Uzel, M.B. Jordan, M. J. Lenardo Chai, LATAIE, New genetic diseases of CTLA-4 checkpoint insufficiency, Blood 128 (2016) $1037-1042$. 
[17] B. Grimbacher, K. Warnatz, P.F.K. Yong, A.S. Korganow, H.H. Peter, The crossroads of autoimmunity and immunodeficiency: lessons from polygenic traits and monogenic defects, J. Allergy Clin. Immunol. 137 (2016) 3-17.

[18] M.R. Zamani, S. Aslani, A. Salmaninejad, M.R. Javan, N. Rezaei, PD-1/PD-L and autoimmunity: a growing relationship, Cell. Immunol. 310 (2016) 27-41.

[19] A. Salmaninejad, V. Khoramshahi, A. Azani, E. Soltaninejad, S. Aslani, M. R. Zamani, et al., PD-1 and cancer: molecular mechanisms and polymorphisms, Immunogenetics 70 (2018) 73-86.

[20] Q. Zhang, D.A. Vignali, Co-stimulatory and co-inhibitory pathways in autoimmunity, Immunity 44 (2016) 1034-1051.

[21] A. Laria, A.M. Lurati, M. Marrazza, D. Mazzocchi, K. Re, M. Scarpellini, The macrophages in rheumatic diseases, J. Inflamm. Res. 9 (2016) 1-11.

[22] V. Malmstrom, A.I. Catrina, L. Klareskog, The immunopathogenesis of seropositive rheumatoid arthritis: from triggering to targeting, Nat. Rev. Immunol. 17 (2017) 60-75.

[23] S. Chaiamnuay, S.L. Bridges Jr., The role of B cells and autoantibodies in rheumatoid arthritis, Pathophysiology 12 (2005) 203-216.

[24] A.P. Cribbs, A. Kennedy, H. Penn, J.E. Read, P. Amjadi, P. Green, et al., Treg cell function in rheumatoid arthritis is compromised by ctla-4 promoter methylation resulting in a failure to activate the indoleamine 2,3-dioxygenase pathway, Arthritis Rheum. 66 (2014) 2344-2354.

[25] N. Legany, L. Berta, L. Kovacs, A. Balog, G. Toldi, The role of B7 family costimulatory molecules and indoleamine 2,3-dioxygenase in primary Sjogren's syndrome and systemic sclerosis, Immunol. Res. 65 (2017) 622-629.

[26] R. Westhovens, Abatacept: the first-in-class costimulation blocker for the treatment of rheumatoid arthritis, Future Medicine (2006) 15-22.

[27] J.S. Smolen, D. Aletaha, A. Barton, G.R. Burmester, P. Emery, G.S. Firestein, et al, Rheumatoid arthritis, Nat Rev Dis Primers 4 (2018) 18001.

[28] M.M. Nielen, D. van Schaardenburg, H.W. Reesink, R.J. van de Stadt, I. van der Horst-Bruinsma, M.H. de Koning, et al., Specific autoantibodies precede the symptoms of rheumatoid arthritis: a study of serial measurements in blood donors, Arthritis Rheum. 50 (2004) 380-386.

[29] L.E. Burgers, H.W. van Steenbergen, R.M. Ten Brinck, T.W. Huizinga, A.H. van der Helm-van Mil, Differences in the symptomatic phase preceding ACPA-positive and ACPA-negative RA: a longitudinal study in arthralgia during progression to clinical arthritis, Ann. Rheum. Dis. 76 (2017) 1751-1754.

[30] A. Kleyer, S. Finzel, J. Rech, B. Manger, M. Krieter, F. Faustini, et al., Bone los before the clinical onset of rheumatoid arthritis in subjects with anticitrullinated protein antibodies, Ann. Rheum. Dis. 73 (2014) 854-860.

[31] A.A. Jilani, C.G. Mackworth-Young, The role of citrullinated protein antibodies in predicting erosive disease in rheumatoid arthritis: a systematic literature review and meta-analysis, Internet J. Rheumatol. 2015 (2015) 728610.

[32] S. Bugatti, L. Bogliolo, B. Vitolo, A. Manzo, C. Montecucco, R. Caporali, Anticitrullinated protein antibodies and high levels of rheumatoid factor are associated with systemic bone loss in patients with early untreated rheumatoid arthritis, Arthritis Res. Ther. 18 (2016) 226.

[33] S. Bugatti, A. Manzo, C. Montecucco, R. Caporali, The clinical value of autoantibodies in rheumatoid arthritis, Front. Med. 5 (2018) 339.

[34] J. Sokolove, M. Schiff, R. Fleischmann, M.E. Weinblatt, S.E. Connolly, A. Johnsen, et al., Impact of baseline anti-cyclic citrullinated peptide-2 antibody concentration on efficacy outcomes following treatment with subcutaneous abatacept or adalimumab: 2-year results from the AMPLE trial, Ann. Rheum. Dis. 75 (2016) 709-714.

[35] C. Wunderlich, I. Oliviera, C.P. Figueiredo, J. Rech, G. Schett, Effects of DMARDs on citrullinated peptide autoantibody levels in RA patients-A longitudinal analysis, Semin. Arthritis Rheum. 46 (2017) 709-714.

[36] D.T.S.L. Jansen, P. Emery, J.S. Smolen, R. Westhovens, M. Le Bars, S.E. Connolly, et al., Conversion to seronegative status after abatacept treatment in patients with early and poor prognostic rheumatoid arthritis is associated with better radiographic outcomes and sustained remission: post hoc analysis of the AGREE study 4, RMD Open, 2018.

[37] L.R. Harrold, H.J. Litman, S.E. Connolly, S. Kelly, W. Hua, E. Alemao, et al., Impact of anti-cyclic citrullinated peptide and rheumatoid factor status on response to abatacept therapy: findings from a US observational cohort, EULAR Annual European Congress of Rheumatology, London, UK, 2016.

[38] Y. Guo, A.M. Walsh, M. Canavan, M.D. Wechalekar, S. Cole, X. Yin, et al., Immune checkpoint inhibitor PD-1 pathway is down-regulated in synovium at various stages of rheumatoid arthritis disease progression, Plos One 13 (2018), e0192704.

[39] M. Ponsoye, C. Frantz, N. Ruzehaji, C. Nicco, M. Elhai, B. Ruiz, et al., Treatmen with abatacept prevents experimental dermal fibrosis and induces regression of established inflammation-driven fibrosis, Ann. Rheum. Dis. 75 (2016) 2142-2149.

[40] M. Kawai, A. Masuda, M. Kuwana, A CD40-CD154 interaction in tissue fibrosis, Arthritis Rheum. 58 (2008) 3562-3573.

[41] P.M. Meiners, A. Vissink, F.G. Kroese, F.K. Spijkervet, N.S. Smitt-Kamminga, W. H. Abdulahad, et al., Abatacept treatment reduces disease activity in early primary Sjogren's syndrome (open-label proof of concept ASAP study), Ann. Rheum. Dis. 73 (2014) 1393-1396.

[42] K. Saegusa, N. Ishimaru, K. Yanagi, N. Haneji, M. Nishino, M. Azuma, et al., Treatment with anti-CD86 costimulatory molecule prevents the autoimmune lesions in murine Sjogren's syndrome (SS) through up-regulated Th2 response, Clin. Exp. Immunol. 119 (2000) 354-360.

[43] C. McDonald-Hyman, L.A. Turka, B.R. Blazar, Advances and challenges in immunotherapy for solid organ and hematopoietic stem cell transplantation, Sci. Transl. Med. 7 (2015), 280rv2.
[44] A.K. Singh, J.P. McGuirk, Allogeneic stem cell transplantation: a historical and scientific overview, Canc. Res. 76 (2016) 6445-6451.

[45] United Network for Organ Sharing. 2018.

[46] A. D'Souza, C. Fretham, Current Uses and Outcomes of Hematopoietic Cell Transplantation (HCT): CIBMTR Summary Slides, 2018 (Summary slides).

[47] T. Alelign, M.M. Ahmed, K. Bobosha, Y. Tadesse, R. Howe, B. Petros, Kidney transplantation: the challenge of human leukocyte antigen and its therapeutic strategies, J Immunol Res 2018 (2018), 5986740.

[48] A. Bharat, T. Mohanakumar, Allopeptides and the alloimmune response, Cell. Immunol. 248 (2007) 31-43.

[49] J.M. DeVos, A.O. Gaber, L.D. Teeter, E.A. Graviss, S.J. Patel, G.A. Land, et al., Intermediate-term graft loss after renal transplantation is associated with both donor-specific antibody and acute rejection, Transplantation 97 (2014) 534-540.

[50] K.M. Karpe, G.S. Talaulikar, G.D. Walters, Calcineurin inhibitor withdrawal or tapering for kidney transplant recipients, Cochrane Database Syst. Rev. 7 (2017), CD006750

[51] W.A. Fabricius, M. Ramanathan, Review on haploidentical hematopoietic cell transplantation in patients with hematologic malignancies, Adv Hematol 2016 (2016), 5726132

[52] S.J. Lee, J. Klein, M. Haagenson, L.A. Baxter-Lowe, D.L. Confer, M. Eapen, et al., High-resolution donor-recipient HLA matching contributes to the success of unrelated donor marrow transplantation, Blood 110 (2007) 4576-4583.

[53] F. Vincenti, Costimulation blockade in autoimmunity and transplantation, J. Allergy Clin. Immunol. 121 (2008) 299-306, quiz 7-8.

[54] D.T. Koura, J.T. Horan, A.A. Langston, M. Qayed, A. Mehta, H.J. Khoury, et al., In vivo $\mathrm{T}$ cell costimulation blockade with abatacept for acute graft-versus-host disease prevention: a first-in-disease trial, Biol. Blood Marrow Transplant. 19 (2013) 1638-1649.

[55] L.S. Kean, A. Langston, M. Qayad, H.J. Khoury, D. Tiwari, C. Couture, et al., CD28-directed T cell costimulation blockade with abatacept to prevent GvHD during high-risk unrelated HSCT: a first-in-disease feasibility trial, Blood, 2011, p. 118.

[56] C.P. Larsen, T.C. Pearson, A.B. Adams, P. Tso, N. Shirasugi, E. Strobert, et al, Rational development of LEA29Y (belatacept), a high-affinity variant of CTLA4-Ig with potent immunosuppressive properties, Am. J. Transplant. 5 (2005) 443-453.

[57] R. Latek, C. Fleener, V. Lamian, E. Kulbokas 3rd, P.M. Davis, S.J. Suchard, et al., Assessment of belatacept-mediated costimulation blockade through evaluation of CD80/86-receptor saturation, Transplantation 87 (2009) 926-933.

[58] M.H. Sayegh, E. Akalin, W.W. Hancock, M.E. Russell, C.B. Carpenter, P.S. Linsley, et al., CD28-B7 blockade after alloantigenic challenge in vivo inhibits Th1 cytokines but spares Th2, J. Exp. Med. 181 (1995) 1869-1874.

[59] A.D. Kirk, D.M. Harlan, N.N. Armstrong, T.A. Davis, Y. Dong, G.S. Gray, et al., CTLA4-Ig and anti-CD40 ligand prevent renal allograft rejection in primates, Proc. Natl. Acad. Sci. U. S. A. 94 (1997) 8789-8794.

[60] A.D. Kirk, L.C. Burkly, D.S. Batty, R.E. Baumgartner, J.D. Berning, K. Buchanan, et al., Treatment with humanized monoclonal antibody against CD154 prevents acute renal allograft rejection in nonhuman primates, Nat. Med. 5 (1999) 686-693.

[61] D.J. Lo, A.B. Farris, M. Song, F. Leopardi, D.J. Anderson, E.A. Strobert, et al., Inhibition of alphavbeta6 promotes acute renal allograft rejection in nonhuman primates, Am. J. Transplant. 13 (2013) 3085-3093.

[62] R.A. Bray, H.M. Gebel, R. Townsend, M.E. Roberts, M. Polinsky, L. Yang, et al., De novo donor-specific antibodies in belatacept-treated vs cyclosporine-treated kidney-transplant recipients: post hoc analyses of the randomized phase III BENEFIT and BENEFIT-EXT studies, Am. J. Transplant. 18 (2018) 1783-1789.

[63] A. Durrbach, J.M. Pestana, T. Pearson, F. Vincenti, V.D. Garcia, J. Campistol, et al., A phase III study of belatacept versus cyclosporine in kidney transplants from extended criteria donors (BENEFIT-EXT study), Am. J. Transplant. 10 (2010) $547-557$.

[64] G. Karadkhele, J. Hogan, W. Magua, W. Zhang, I.R. Badell, A. Mehta, et al., CMV high-risk status and post-transplant outcomes in kidney transplant recipients treated with Belatacept, Am J Transplant, 2020.

[65] J. Espinosa, F. Herr, G. Tharp, S. Bosinger, M. Song, A.B. Farris 3rd, et al., CD57( +) CD4 T cells underlie belatacept-resistant allograft rejection, Am. J. Transplant. 16 (2016) 1102-1112.

[66] A.B. Adams, M.A. Williams, T.R. Jones, N. Shirasugi, M.M. Durham, S.M. Kaech, et al., Heterologous immunity provides a potent barrier to transplantation tolerance, J. Clin. Invest. 111 (2003) 1887-1895.

[67] H. Xu, K.P. Samy, A. Guasch, S.I. Mead, A. Ghali, A. Mehta, et al., Postdepletion lymphocyte reconstitution during belatacept and rapamycin treatment in kidney transplant recipients, Am. J. Transplant. 16 (2016) 550-564.

[68] A.D. Kirk, A. Guasch, H. Xu, J. Cheeseman, S.I. Mead, A. Ghali, et al., Rena transplantation using belatacept without maintenance steroids or calcineurin inhibitors, Am. J. Transplant. 14 (2014) 1142-1151.

[69] J. Kwun, J. Park, J.S. Yi, A.B. Farris, A.D. Kirk, S.J. Knechtle, IL-21 biased alemtuzumab induced chronic antibody-mediated rejection is reversed by LFA-1 costimulation blockade, Front. Immunol. 9 (2018) 2323.

[70] R. Schmitz, Z.W. Fitch, H. Xu, A. Ghali, A.K. Mehta, A. Guasch, et al., Kidney transplantation using alemtuzumab, belatacept, and sirolimus: five-year followup, Am. J. Transplant. (2020), https://doi.org/10.1111/ajt.16121.

[71] B.K. Watkins, V. Tkachev, S.N. Furlan, D.J. Hunt, K. Betz, A. Yu, et al., CD28 blockade controls $\mathrm{T}$ cell activation to prevent graft-versus-host disease in primates, J. Clin. Invest. 128 (2018) 3991-4007.

[72] B. Watkins, M. Qayed, B. Bratrude, K. Betz, M. Brown, J. Rhodes, et al., T cell costimulation blockade with abatacept nearly eliminates early severe acute GVHD after HLA-mismathced (7/8 HLA matched) URD BMT with a favorable 
impact on disease-free and overall survival, American Society of Hematology Annual Meeting, Washington, D.C. USA, 2017.

[73] A.F. Zahorchak, L.S. Kean, D. Tokita, H.R. Turnquist, M. Abe, J. Finke, et al., Infusion of stably immature monocyte-derived dendritic cells plus CTLA4Ig modulates alloimmune reactivity in rhesus macaques, Transplantation 84 (2007) 196-206.

[74] F. Bray, J. Ferlay, I. Soerjomataram, R.L. Siegel, L.A. Torre, A. Jemal, Global cancer statistics 2018: GLOBOCAN estimates of incidence and mortality worldwide for 36 cancers in 185 countries, CA A Cancer J. Clin. 68 (2018) 394-424.

[75] M.D. Vesely, M.H. Kershaw, R.D. Schreiber, M.J. Smyth, Natural innate and adaptive immunity to cancer, Annu. Rev. Immunol. 29 (2011) 235-271.

[76] M.R. Zocchi, C. Camodeca, E. Nuti, A. Rossello, R. Vene, F. Tosetti, et al. ADAM10 new selective inhibitors reduce NKG2D ligand release sensitizing Hodgkin lymphoma cells to NKG2D-mediated killing, OncoImmunology 5 (2016), e1123367.

[77] Z. Guo, X. Wang, D. Cheng, Z. Xia, M. Luan, S. Zhang, Correction: PD-1 blockade and OX40 triggering synergistically protects against tumor growth in a murine model of ovarian cancer, PloS One 12 (2017), e0186965.

[78] J.M. Kirkwood, L.H. Butterfield, A.A. Tarhini, H. Zarour, P. Kalinski, S. Ferrone Immunotherapy of cancer in 2012, CA A Cancer J. Clin. 62 (2012) 309-335.

[79] T.F. Gajewski, H. Schreiber, Y.X. Fu, Innate and adaptive immune cells in the tumor microenvironment, Nat. Immunol. 14 (2013) 1014-1022.

[80] D.Y. Oh, J. Cham, L. Zhang, G. Fong, S.S. Kwek, M. Klinger, et al., Immune toxicities elicted by CTLA-4 blockade in cancer patients are associated with early diversification of the T-cell repertoire, Canc. Res. 77 (2017) 1322-1330.

[81] B.-M. Squibb, Yervoy® (Ipilimumab) Injection, for Intravenous Use, Princeton, NJ USA, 2011. revised April 2018.

[82] J. Retseck, R. VanderWeele, H.M. Lin, Y. Lin, L.H. Butterfield, A.A. Tarhini, Phenotypic and functional testing of circulating regulatory $\mathrm{T}$ cells in advanced melanoma patients treated with neoadjuvant ipilimumab, J. Immunother. Canc. 4 (2016) 38.

[83] S.J. Antonia, J.F. Vansteenkiste, E. Moon, Immunotherapy: beyond anti-PD-1 and anti-PD-L1 therapies, Am. Soc. Clin. Oncol. Educ. Book 35 (2016) e450-e458.

[84] K. Ghate, E. Amir, M. Kuksis, D. Hernandez-Barajas, L. Rodriguez-Romo, C. M. Booth, et al., PD-L1 expression and clinical outcomes in patients with advanced urothelial carcinoma treated with checkpoint inhibitors: a metaanalysis, Canc. Treat Rev. 76 (2019) 51-56.

[85] J. Barclay, J. Creswell, J. Leon, Cancer immunotherapy and the PD-1/PD-L1 checkpoint pathway, Arch. Esp. Urol. 71 (2018) 393-399.

[86] S. Bracarda, A. Altavilla, A. Hamzaj, M. Sisani, F. Marrocolo, S. Del Buono, et al. Immunologic checkpoints blockade in renal cell, prostate, and urothelial malignancies, Semin. Oncol. 42 (2015) 495-505.

[87] F. Massari, M. Santoni, C. Ciccarese, D. Santini, S. Alfieri, G. Martignoni, et al, PD-1 blockade therapy in renal cell carcinoma: current studies and future promises, Canc. Treat Rev. 41 (2015) 114-121.

[88] J.D. Wolchok, V. Chiarion-Sileni, R. Gonzalez, P. Rutkowski, J.J. Grob, C. L. Cowey, et al., Overall survival with combined nivolumab and ipilimumab in advanced melanoma, N. Engl. J. Med. 377 (2017) 1345-1356.

[89] R.J. Motzer, N.M. Tannir, D.F. McDermott, O. Aren Frontera, B. Melichar, T. K. Choueiri, et al., Nivolumab plus ipilimumab versus sunitinib in advanced renal-cell carcinoma, N. Engl. J. Med. 378 (2018) 1277-1290.

[90] M.D. Hellmann, T.E. Ciuleanu, A. Pluzanski, J.S. Lee, G.A. Otterson, C. AudigierValette, et al., Nivolumab plus ipilimumab in lung cancer with a high tumor mutational burden, N. Engl. J. Med. 378 (2018) 2093-2104.

[91] N. McGranahan, A.J. Furness, R. Rosenthal, S. Ramskov, R. Lyngaa, S.K. Saini, et al., Clonal neoantigens elicit T cell immunoreactivity and sensitivity to immune checkpoint blockade, Science 351 (2016) 1463-1469.

[92] N.A. Rizvi, M.D. Hellmann, A. Snyder, P. Kvistborg, V. Makarov, J.J. Havel, et al., Cancer immunology. Mutational landscape determines sensitivity to PD-1 blockade in non-small cell lung cancer, Science 348 (2015) 124-128.

[93] A.W. Hahn, R.H. Nussenzveig, S.K. Pal, N. Agarwal, Blood- and tissue-based tumor genomics: a battle royale or match made in heaven? Ann. Oncol. 28 (2017) 2333-2335.

[94] B. Rowshanravan, N. Halliday, D.M. Sansom, CTLA-4: a moving target in immunotherapy, Blood 131 (2018) 58-67.

[95] B.L. Mangan, R.K. McAlister, J.M. Balko, D.B. Johnson, J.J. Moslehi, A. Gibson, et al., Evolving insights into the mechanisms of toxicity associated with immune checkpoint inhibitor therapy, Br. J. Clin. Pharmacol. (2020), https://doi.org/ 10.1111/bcp.14433.

[96] J.M. Michot, C. Bigenwald, S. Champiat, M. Collins, F. Carbonnel, S. Postel-Vinay, et al., Immune-related adverse events with immune checkpoint blockade: a comprehensive review, Eur. J. Canc. 54 (2016) 139-148.

[97] C.H. June, J.T. Warshauer, J.A. Bluestone, Is autoimmunity the Achilles' heel of cancer immunotherapy? Nat. Med. 23 (2015) 540-548.

[98] L.C. Cappelli, A.K. Gutierrez, C.O. Bingham 3rd, A.A. Shah, Rheumatic and musculoskeletal immune-related adverse events due to immune checkpoint inhibitors: a systematic review of the literature, Arthritis Care Res. 69 (2017) 1751-1763.

[99] L.C. Cappelli, A.A. Shah, C.O. Bingham 3rd, Immune-related adverse effects of cancer immunotherapy- implications for rheumatology, Rheum. Dis. Clin. N. Am. 43 (2017) 65-78.

[100] F. Gediz, S. Kobak, Immune checkpoint inhibitors-related rheumatic diseases: what rheumatologist should know? Curr. Rheumatol. Rev. 15 (3) (2019) 201-208.
[101] A. Young, Z. Quandt, J.A. Bluestone, The balancing act between cancer immunity and autoimmunity in response to immunotherapy, Cancer Immunol. Res. 6 (2018) 1445-1452.

[102] L.H. Calabrese, C. Calabrese, L.C. Cappelli, Rheumatic immune-related adverse events from cancer immunotherapy, Nat. Rev. Rheumatol. 14 (2018) 569-579.

[103] E.P. Hoefsmit, E.A. Rozeman, J. Haanen, C.U. Blank, Susceptible loci associated with autoimmune disease as potential biomarkers for checkpoint inhibitor induced immune-related adverse events, ESMO Open 4 (2019), e000472.

[104] J. Haanen, F. Carbonnel, C. Robert, K.M. Kerr, S. Peters, J. Larkin, et al. Management of toxicities from immunotherapy: ESMO Clinical Practice Guidelines for diagnosis, treatment and follow-up, Ann. Oncol. 28 (2017) iv119-i142.

[105] M. Tocut, R. Brenner, G. Zandman-Goddard, Autoimmune phenomena and disease in cancer patients treated with immune checkpoint inhibitors, Autoimmun. Rev. 17 (2018) 610-616.

[106] S. Cousin, A. Italiano, Molecular pathways: immune checkpoint antibodies and their toxicities, Clin. Canc. Res. 22 (2016) 4550-4555.

[107] M.E. Weinblatt, L.W. Moreland, R. Westhovens, R.B. Cohen, S.M. Kelly, N. Khan, et al., Safety of abatacept administered intravenously in treatment of rheumatoid arthritis: integrated analyses of up to 8 years of treatment from the abatacept clinical trial program, J. Rheumatol. 40 (2013) 787-797.

[108] G. Ozen, S. Pedro, R. Schumacher, T.A. Simon, K. Michaud, Safety of abatacept compared with other biologic and conventional synthetic disease-modifying antirheumatic drugs in patients with rheumatoid arthritis: data from an observational study, Arthritis Res. Ther. 21 (2019) 141.

[109] K. Elandt, D. Aletaha, Treating rheumatic patients with a malignancy, Arthritis Res. Ther. 13 (2011) 223.

[110] R.J. Zogala, K. Goutsouliak, M.E. Suarez-Almazor, Management considerations in cancer patients with rheumatoid arthritis, Oncology (Williston Park) 31 (2017) 374-380.

[111] L. Calabrese, X. Mariette, The evolving role of the rheumatologist in the management of immune-related adverse events (irAEs) caused by cancer immunotherapy, Ann. Rheum. Dis. 77 (2018) 162-164.

[112] E. Efuni, S. Cytryn, P. Boland, T.B. Niewold, A. Pavlick, J. Weber, et al., Risk of toxicity after initiating immune checkpoint inhibitor treatment in patients with rheumatoid arthritis, J. Clin. Rheumatol. (2020).

[113] K.L. Kehl, S. Yang, M.M. Awad, N. Palmer, I.S. Kohane, D. Schrag, Pre-existing autoimmune disease and the risk of immune-related adverse events among patients receiving checkpoint inhibitors for cancer, Cancer Immunol Immunother, 2019.

[114] N. Abdel-Wahab, M. Shah, M.A. Lopez-Olivo, M.E. Suarez-Almazor, Use of immune checkpoint inhibitors in the treatment of patients with cancer and preexisting autoimmune disease: a systematic review, Ann. Intern. Med. 168 (2018) 121-130.

[115] E.A. Engels, R.M. Pfeiffer, J.F. Fraumeni Jr., B.L. Kasiske, A.K. Israni, J.J. Snyder, et al., Spectrum of cancer risk among US solid organ transplant recipients, J. Am. Med. Assoc. 306 (2011) 1891-1901.

[116] Y.K. Chae, C. Galvez, J.F. Anker, W.T. Iams, M. Bhave, Cancer immunotherapy in a neglected population: the current use and future of T-cell-mediated checkpoint inhibitors in organ transplant patients, Canc. Treat Rev. 63 (2018) 116-121.

[117] P. De Bruyn, D. Van Gestel, P. Ost, V. Kruse, L. Brochez, H. Van Vlierberghe, et al, Immune checkpoint blockade for organ transplant patients with advanced cancer: how far can we go? Curr. Opin. Oncol. 31 (2) (2019) 54-64.

[118] D.B. Johnson, R.J. Sullivan, A.M. Menzies, Immune checkpoint inhibitors in challenging populations, Cancer 123 (2017) 1904-1911.

[119] N. Abdel-Wahab, H. Safa, A. Abudayyeh, D.H. Johnson, V.A. Trinh, C.M. Zobniw, et al., Checkpoint inhibitor therapy for cancer in solid organ transplantation recipients: an institutional experience and a systematic review of the literature, J. Immunother. Canc. 7 (2019) 106.

[120] E.P. Darnell, M.J. Mooradian, E.N. Baruch, M. Yilmaz, K.L. Reynolds, Immunerelated adverse events (irAEs): diagnosis, management, and clinical pearls, Curr. Oncol. Rep. 22 (2020) 39.

[121] J. Roberts, D. Ennis, M. Hudson, C. Ye, A. Saltman, R. Rottapel, et al., Rheumatic immune-related adverse events associated with cancer immunotherapy: a nationwide multi-center cohort, Autoimmun. Rev. (2020), 102595.

[122] S.T. Kim, J. Tayar, V.A. Trinh, M. Suarez-Almazor, S. Garcia, P. Hwu, et al., Successful treatment of arthritis induced by checkpoint inhibitors with tocilizumab: a case series, Ann. Rheum. Dis. 76 (2017) 2061-2064.

[123] M. Lidar, E. Giat, D. Garelick, Y. Horowitz, H. Amital, Y. Steinberg-Silman, et al., Rheumatic manifestations among cancer patients treated with immune checkpoint inhibitors, Autoimmun. Rev. 17 (2018) 284-289.

[124] X. Pundole, N. Abdel-Wahab, M.E. Suarez-Almazor, Arthritis risk with immune checkpoint inhibitor therapy for cancer, Curr. Opin. Rheumatol. 31 (2019) 293-299.

[125] C. Xu, Y.P. Chen, X.J. Du, J.Q. Liu, C.L. Huang, L. Chen, et al., Comparative safety of immune checkpoint inhibitors in cancer: systematic review and network metaanalysis, BMJ 363 (2018) k4226.

[126] N.K. Patil, Y. Guo, L. Luan, E.R. Sherwood, Targeting immune cell checkpoints during sepsis, Int. J. Mol. Sci. 18 (2017).

[127] L.M. Juarez-Salcedo, S. Dalia, Use of check-point inhibitors in the treatment of progressive multifocal leukoencephalopathy, Ann. Transl. Med. 7 (2019) S297.

[128] L. Dyck, K.H.G. Mills, Immune checkpoints and their inhibition in cancer and infectious diseases, Eur. J. Immunol. 47 (2017) 765-779.

[129] R.C. Hoogeveen, A. Boonstra, Checkpoint inhibitors and therapeutic vaccines for the treatment of chronic HBV infection, Front. Immunol. 11 (2020) 401. 
[130] M. Rao, D. Valentini, E. Dodoo, A. Zumla, M. Maeurer, Anti-PD-1/PD-L1 therapy for infectious diseases: learning from the cancer paradigm, Int. J. Infect. Dis. 56 (2017) 221-228.

[131] I. Cortese, P. Muranski, Y. Enose-Akahata, S.K. Ha, B. Smith, M. Monaco, et al., Pembrolizumab treatment for progressive multifocal leukoencephalopathy, N. Engl. J. Med. 380 (2019) 1597-1605.

[132] J.A. Marin-Acevedo, B. Dholaria, A.E. Soyano, K.L. Knutson, S. Chumsri, Y. Lou, Next generation of immune checkpoint therapy in cancer: new developments and challenges, J. Hematol. Oncol. 11 (2018) 39.

[133] R. Saleh, E. Elkord, Acquired resistance to cancer immunotherapy: role of tumor mediated immunosuppression, Semin. Canc. Biol. 65 (2019) 13-27.

[134] P. Darvin, S.M. Toor, V. Sasidharan Nair, E. Flkord, Immune checkpoint inhibitors: recent progress and potential biomarkers, Exp. Mol. Med. 50 (2018) $1-11$.

[135] S. Mariathasan, S.J. Turley, D. Nickles, A. Castiglioni, K. Yuen, Y. Wang, et al., TGFbeta attenuates tumour response to PD-L1 blockade by contributing to exclusion of T cells, Nature 554 (2018) 544-548.

[136] K. Ganesh, J. Massague, TGF-beta inhibition and immunotherapy: checkmate, Immunity 48 (2018) 626-628.

[137] D.J. Lo, T.A. Weaver, L. Stempora, A.K. Mehta, M.L. Ford, C.P. Larsen, et al., Selective targeting of human alloresponsive CD $8+$ effector memory T cells based on CD2 expression, Am. J. Transplant. 11 (2011) 22-33.

[138] M. Cortes-Cerisuelo, S.J. Laurie, D.V. Mathews, P.D. Winterberg, C.P. Larsen, A. B. Adams, et al., Increased pretransplant frequency of CD28(+) CD4(+) TEM predicts belatacept-resistant rejection in human renal transplant recipients, Am. J. Transplant. 17 (2017) 2350-2362.

[139] Y. Wolf, Y. Samuels, Cancer research in the era of immunogenomics, ESMO Open 3 (2018), e000475.

[140] J. Gong, A. Chehrazi-Raffle, S. Reddi, R. Salgia, Development of PD-1 and PD-L1 inhibitors as a form of cancer immunotherapy: a comprehensive review of registration trials and future considerations, J. Immunother. Canc. 6 (2018) 8.

[141] E. Gonzalez-Gugel, M. Saxena, N. Bhardwaj, Modulation of innate immunity in the tumor microenvironment, Cancer Immunol. Immunother. 65 (2016) $1261-1268$.

[142] S. Kurtulus, A. Madi, G. Escobar, M. Klapholz, J. Nyman, E. Christian, et al., Checkpoint blockade immunotherapy induces dynamic changes in PD-1(-)CD8(+) tumor-infiltrating T cells, Immunity 50 (2019) 181-194 e6.
[143] B.C. Miller, D.R. Sen, R. Al Abosy, K. Bi, Y.V. Virkud, M.W. LaFleur, et al., Subsets of exhausted CD8( + ) T cells differentially mediate tumor control and respond to checkpoint blockade, Nat. Immunol. 20 (2019) 326-336.

[144] D.S. Thommen, V.H. Koelzer, P. Herzig, A. Roller, M. Trefny, S. Dimeloe, et al., A transcriptionally and functionally distinct PD-1 $(+)$ CD8 $(+)$ T cell pool with predictive potential in non-small-cell lung cancer treated with PD-1 blockade, Nat. Med. 24 (2018) 994-1004.

[145] N. Riaz, J.J. Havel, V. Makarov, A. Desrichard, W.J. Urba, J.S. Sims, et al., Tumor and microenvironment evolution during immunotherapy with nivolumab, Cell 171 (2017) 934-949 e16.

[146] M.H. Ravindranath, E.J. Filippone, A. Devarajan, S. Asgharzadeh, Enhancing natural killer and CD8(+) T cell-mediated anticancer cytotoxicity and proliferation of CD8(+) T cells with HLA-E monospecific monoclonal antibodies, Monoclon. Antibodies Immunodiagn. Immunother. 38 (2019) 38-59.

[147] J. Freund-Brown, L. Chirino, T. Kambayashi, Strategies to enhance NK cell function for the treatment of tumors and infections, Crit. Rev. Immunol. 38 (2018) 105-130

[148] R. Barroso-Sousa, P.A. Ott, Transformation of old concepts for a new era of cancer immunotherapy: cytokine therapy and cancer vaccines as combination partners of PD1/PD-L1 inhibitors, Curr. Oncol. Rep. 21 (1) (2018).

[149] J.N. Choi, E.G. Sun, S.H. Cho, IL-12 enhances immune response by modulation of myeloid derived suppressor cells in tumor microenvironment, Chonnam. Med. J. 55 (2019) 31-39.

[150] J.T. Merrill, D.E. Shevell, D. Duchesne, M. Nowak, S. Kundu, I.G. Girgis, et al., An anti-CD28 domain antibody, lulizumab, in: Systemic Lupus Erythematosus: Results of a Phase II Study. 2018 ACR/ARHP Annual Meeting, Arthritis Rheumatol, Chicago, IL, 2018.

[151] M. Uehara, M.M. McGrath, The role of costimulatory pathways in transplant tolerance, Clin. Lab. Med. 39 (2019) 87-106.

[152] M.H. Yamada, Sayegh, The CD154-CD40 costimulatory pathway in transplantation, Transplantation 73 (2002) S36-S39.

[153] D. Bojadzic, P. Buchwald, Toward small-molecule inhibition of protein-protein interactions: general aspects and recent progress in targeting costimulatory and coinhibitory (immune checkpoint) interactions, Curr. Top. Med. Chem. 18 (2018) 674-699.

[154] V. Malmstrom, C. Trollmo, L. Klareskog, Modulating co-stimulation: a rational strategy in the treatment of rheumatoid arthritis? Arthritis Res. Ther. 7 (Suppl 2) (2005) S15-S20. 